\title{
Nutritional Scenario of Adolescent Boys in Dhaka University Campus
}

\author{
Lutfun Nahar ${ }^{*}$ and Nazma Parvin \\ Institute of Nitration and Food Science, University of Dhaka, Dhaka
}

\begin{abstract}
A cross sectional study was carried out among the adolescent boys (11-15 years) in two selective schools (University Laboratory School and Udoyan School) in Dhaka University campus to investigate the nutritional and health status as well as socioeconomic condition. Nutritional status was determined anthropometrically and biochemically (hemoglobin estimation). According to the body mass index, two-third of the boys $(75.7 \%)$ were normal, $15.4 \%$ were over-weight and only $8.9 \%$ were found to be thinner. The percent prevalence of anemia was $7.1 \%$ based on WHO criteria and the mean hemoglobin level was $14.35 \mathrm{~g} / \mathrm{dl}( \pm 1.38)$. Energy intake of the boys aged $11-12$ years met $79.31 \%$ of RDA and those of $13-15$ years met $76.09 \%$ of RDA. Protein intake of all the boys was more than RDA. Dietary intake of vitamin A was more than $90 \%$ of RDA. and that for thiamin and niacin was more than RDA. Iron intake was $60.4 \%$ and $66.45 \%$ of RDA for the two groups of boys. Vitamin C intake was inadequate $(46.76 \%$ and $36.06 \%$ RDA) for the respective group of boys. Nutritional status (anthropometric) is directly associated with expenditure on food. Percentage of thinness decreased as expenditure on food increased. Monthly expenditure on food had significant relation with hemoglobin level of the adolescents. Most of the participants $(67.5 \%)$ did not suffer from any disease. Rest of the boys suffered from fever $(23.6 \%)$, diarrhea $(10.9 \%)$, common cold $(29.1 \%)$, respiratory infection $(9.1 \%)$, measles $(3.6 \%)$, typhoid $(5.5 \%)$ and others $(18.2 \%)$.
\end{abstract}

Key words: Adolescent boys, Nutritional status, Dhaka University Campus School.

\section{Introduction:}

Adolescence is the period from childhood to adulthood. It is the period of life between 10-19 years of age and is characterized by dramatic change in physical, biochemical and emotional development. Growth spurt during adolescence varies in intensity and duration for individual due to several factors such as heredity, environment, socio-economic status, illness and nutritional status in childhood ${ }^{1}$. The health status and needs of adolescents have until recently been largely neglected. With improvements of under five mortality, world attention is now shifted to the health of school aged children

Bangladesh Journal of Nutrition. Vol 18-19, December 2005-2006. Institute of Nutrition and Food Science, University of Dhaka-1000, Bangladesh.

\footnotetext{
Author for correspondence
} 
as well as adolescents. In developing countries these children are malnourished, anaemic and have infectious and parasitic disease burdens that hamper growth and development. The major work ${ }^{2,3}$ in the field of adolescent nutrition in developing countries was carried out in eleven countries under the co-ordination of the International Center for Research on Woman (ICRW). Stunting was highly prevalent in nine of the ICRW studies. Thinness was highly prevalent in only three of the countries studied. Adolescents in developing countries join the work force, get married and become pregnant early ${ }^{4}$. In addition to growth retardation, iron deficiency anaemia is also a well-recognized problem for adolescent worldwide.

Adolescents are prone to develop iron deficiency anaemia because of menarche and rapid growth. It has been estimated from a review of 39 studies $^{5}$ that $27 \%$ of adolescents are anaemic in developing countries and $6 \%$ are anaemic in developed countries. More recent work ${ }^{6}$ identifies anaemia as the greatest nutritional problem for adolescent in four out of a unique opportunity for the schools to promote and improve the health of the students by instructing them the principles of healthful living by appraising their health status.

\section{Methodology}

Study design: A cross sectional study was conducted on the adolescent boys of schools within Dhaka University campus. Selected schools were University Laboratory School and Udoyon School.

Study population: Students were briefed about the study. Boys (11-15 years) who were interested were selected for this purpose. Each of the selected students was handed a letter seeking permission of the guardian to include their children in the study. One hundred and sixty nine adolescent boys were selected randomly.

The questionnaire: In order to obtain relevant socio-economic data, personal characteristics and general health information, a standard questionnaire was developed. Dietary intake was recorded by " 24 hour" recall method. The questionnaire was pretested before finalization. The data and specimen was collected during school hours in school premises. Part of the questionnaire (part one) was filled up by the parents for socioeconomic information. Rest of the data (part two) was collected by interviewing the subjects.

Blood collection: Blood was collected through finger prick. Hemoglobin levels were estimated by cyanmethemoglobin method ${ }^{7.8}$ using a commercially available kit (Boehringner, Manheim, Germany).

Anthropometric measurement: Height and weight of the subjects were measured by standard scale (Detecto-Medic, Detecto scales INC, USA). The Body Mass Index (BMI) was calculated from the body weight of the subjects using the formula:

$\mathrm{BMI}=\left(\right.$ Weight of the subject in $\mathrm{Kg} \div$ Height of the subject in meter ${ }^{2}$ ) 


\section{Results}

The study was carried out in two schools within Dhaka University Campus. Majority of the students (59.8\%) were from University Laboratory School and $40.2 \%$ of the boys were student of Udoyon School. Characteristics of the boys as shown in Table 1

Table 1. Characteristics of the study population

\begin{tabular}{|l|c|}
\hline \multicolumn{1}{|c|}{ Parameters } & Percentage \\
\hline School & \\
Udoyan & 40.2 \\
University Laboratory School & 59.8 \\
\hline Age & \\
11-12 years & 31 \\
$13-15$ years & 69 \\
\hline Classes & \\
Class VII & 29 \\
Class VIII & 46 \\
Class IX & 25 \\
\hline
\end{tabular}

Table 2. Percent distribution of the study participants by their Father's occupation

\begin{tabular}{|l|c|c|}
\hline \multicolumn{1}{|c|}{ Professions } & Number & Percentage \\
\hline Teacher / Officer / Doctor / Engineer & 75 & 44.4 \\
\hline Employee/ Service & 46 & 27.2 \\
\hline Business & 45 & 26.6 \\
\hline Not applicable & 3 & 1.8 \\
\hline
\end{tabular}

Table 3. Percent distribution of the study participants by their Mother's occupation

\begin{tabular}{|l|c|c|}
\hline \multicolumn{1}{|c|}{ Professions } & Number $(\mathbf{n}=)$ & Percentage \\
\hline Teacher/ Officer / Doctor / Engineer & 31 & 18.3 \\
\hline Employee / Service & 8 & 4.7 \\
\hline Business & 3 & 1.8 \\
\hline House wife & 127 & 75.1 \\
\hline
\end{tabular}

Table 4. Percent distribution of the study participants by the Family Monthly Expenditure on food.

\begin{tabular}{|l|c|c|}
\hline \multicolumn{1}{|c|}{ Expenditure (Taka) } & Number & Percentage \\
\hline$<5000$ & 36 & 21.3 \\
\hline $5000-7499$ & 82 & 48.5 \\
\hline $7500-9999$ & 32 & 18.9 \\
\hline$>10000$ & 19 & 11.2 \\
\hline
\end{tabular}

Table 5. Percent distribution of the study population by nutritional status.(BMI)

\begin{tabular}{|l|c|c|}
\hline \multicolumn{1}{|c|}{ Nutritional status } & Number & Percentage \\
\hline Thinness & 15 & 8.9 \\
\hline Normal & 128 & 75.7 \\
\hline Over weight & 26 & 15.4 \\
\hline
\end{tabular}


Table 6. Hemoglobin level of the study participants by their age groups.

\begin{tabular}{|l|c|c|c|c|c|}
\hline \multirow{2}{*}{ Age groups } & \multicolumn{5}{|c|}{ Hemoglobin (gm/dl) } \\
\cline { 2 - 6 } & Mean & \pm SD & Median & Minimum & Maximum \\
\hline $11-12$ years & 14.45 & 1.31 & 14039 & 10.49 & 17.16 \\
\hline $13-15$ years & 14.31 & 1.41 & 14.36 & 11.19 & 18.08 \\
\hline
\end{tabular}

Table 7. Percent distribution of the study participants according to their type of diseases.

\begin{tabular}{|l|c|c|}
\hline \multicolumn{1}{|c|}{ Type of diseases } & Number & Percentage \\
\hline Fever & 13 & 23.6 \\
\hline Cold fever & 16 & 29.1 \\
\hline Diarhoea & 6 & 10.9 \\
\hline $\begin{array}{l}\text { Respiratory infectious } \\
\text { diseases }\end{array}$ & 5 & 9.1 \\
\hline Measles & 2 & 3.6 \\
\hline Typhoid & 3 & 5.5 \\
\hline Others & 16 & 18.2 \\
\hline
\end{tabular}

Table 8. Comparison of daily food intake between age group (11-12) \& (13-15) years with meeting of RDA \%

\begin{tabular}{|l|c|c|c|c|c|c|c|c|}
\hline \multicolumn{1}{|c|}{ Nutrients } & \multicolumn{3}{|c|}{ Age 11-12 years } & \multicolumn{3}{c|}{ Age 13-15 years } \\
\hline & Mean & ISD & RDA & $\begin{array}{l}\text { Meetin } \\
\text { g\% of } \\
\text { RDA }\end{array}$ & Mean & ISD & $\begin{array}{l}\text { RDA } \\
\text { g\% of } \\
\text { RDA }\end{array}$ \\
\hline Calorie (Kcal) & 1561.8 & $\begin{array}{c}258.3 \\
7\end{array}$ & 1969 & 79.31 & $\begin{array}{c}1635.9 \\
8\end{array}$ & 313.94 & 2150 & 76.09 \\
\hline Protein (gm) & 42.12 & 12.70 & 41.5 & 101.49 & 45.36 & 14.18 & 44.2 & 102.62 \\
\hline Fat(gm) & 325.74 & $\begin{array}{c}430.0 \\
1\end{array}$ & 650 & 50.11 & 322.87 & 14.65 & 22 & 99.64 \\
\hline Ca(mg) & 11.80 & 4.25 & 24 & 49.17 & 11.94 & 5.68 & 29 & 41.17 \\
\hline VitA(ngm) & 539.38 & 738.9 & 600 & 89.90 & 827.68 & 2325.2 & 600 & 137.95 \\
\hline Thiamin(mg) & 1.04 & .21 & 1.00 & 103.48 & 1.07 & 0.26 & 1.073 & 99.72 \\
\hline Riboflaving(mg) & 0.63 & 0.62 & 1.20 & 52.5 & 0.65 & 0.66 & 1.29 & 50.39 \\
\hline Niacin(mg) & 14.71 & 2.02 & 13.3 & 110.60 & 15.92 & 2.46 & 14.17 & 112.35 \\
\hline Vit-C(mg) & 23.38 & 19.75 & 50 & 46.76 & 18.03 & 15.01 & 50 & 36.06 \\
\hline
\end{tabular}

indicate that $31 \%$ of the boys belong to the age group $11-12$ years and $69 \%$ were in the age group 13-15 years. Regarding the classes attending in school most of the students $(46 \%)$ were in class VIII. On the other hand, the boys in class VII and class IX were $29 \%$ and $25 \%$ respectively. A significant number $(44.4 \%)$ of the participant's father were high officials (Teacher/Officer/ Doctor/Engineer). Similar proportion of the fathers were other service holder $(27.2 \%)$ and businessman $(26.6 \%)$. Table 3. represents the occupation of the mothers of the participants. Two-third $(75.1 \%)$ of the mothers were house wife, whereas $18.3 \%$ were high officials and $4.7 \%$ were other service holder. Only 3 mothers 
were involved in business. Table 4 . depicts that monthly expenditure on food for about half $(48.5 \%)$ of the families studied were between Tk. 5000/-7499/. On the other hand $21.3 \%$ families spent less than Tk.5000/- and $18.9 \%$ spent Tk.7500/-9999/ per month. Monthly expenditure on food Tk. 10,000/- was only for 9 families (11.2\%). Nutritional status of the adolescent boys (Table 5.) indicates that two-third $(75.7 \%)$ of the boys were nutritionally sound anthropometrically having normal BMI according to age. Prevalence of over weight $(15.4 \%)$ was more than the prevalence of thinness $(8.9 \%)$. Median value of hemoglobin (Table 6.) for the boys of 11-12 years and 13-15 years was $14.39 \mathrm{~g} / \mathrm{dl}$ and $14.36 \mathrm{~g} / \mathrm{dl}$ respectively. Only $7.1 \%$ boys were anemic (hemoglobin level below cut off point). Morbidity rate was $32 \%$ (Table 7). The boys suffered from fever $(23.6 \%)$, cold and fever $(29.1 \%)$, diarrhea $(10.9 \%)$, respiratory infectious disease $(9.1 \%)$, measles $(3.6 \%)$ and typhoid $(5.5 \%)$ and others $(18.2 \%)$. Table 8 . represents the mean dietary intake of two groups of adolescent boys aged 11-12 years and 13-15 years respectively. The mean energy intake for the two groups were $1561.8 \mathrm{Kcal}$ and $1635.98 \mathrm{Kcal}$ which met $79.31 \%$ and $76.09 \%$ of the recommended allowance. The mean protein intake was $42.12 \mathrm{~g}$ and $45.3 \mathrm{~g}$ which was more than the requirement (RDA). Intake of fat which may be considered as the reflection of economic condition was satisfactory $(93 \%$ and $99.66 \%$ of RDA). Regarding micronutrients, dietary intake of thiamin and niacin was more than RDA and that for vitamin A was more than $90 \%$ of RDA for the two groups of boys. On the other hand intake of iron, copper, riboflavin and vitamin $\mathrm{C}$ was comparatively low which fulfilled about $40-50 \%$ of recommended allowance.

\section{Discussion}

In Bangladesh about one fourth of total population are adolescents. It is well documented that the growth velocity during adolescent is slower in undernourished population. Protein energy malnutrition as well as iron defiency may be a limiting factor for growth during adolescence. In the present study majority of the boys came from educated families with relatively higher social position and better economic conditions; and it did not include boys from urban poor. In the present study nutritional status of most Nutritional status of adolescent boys of the present study are better than that of the boys in the previous national survey. Better socio-economic status may be the main reason for better growth achievement of the participants. A significant number $(44.4 \%)$ of the participant's father were high official (Teacher/Doctor/Officer/Engineer), $27.2 \%$ were employee of Government or non-Government offices and $26.6 \%$ were businessman. Educational level of the participant's mothers were comparatively high. Only $16.65 \%$ were below SSC and $46.2 \%$ passed HSC, $21.95 \%$ were graduate. Whereas $15.4 \%$ received master degree or above.

The overall prevalence of anemia in the present study was $7.1 \%$, based on WHO criteria. None of the participants was severely anemic (hemoglobin level $<7.0 \mathrm{gdl}$ ). Findings of a study conducted by Hyder et.al(9) reveals that prevalence of anemia in a rural community of Bangladesh was $69 \%$. The national nutrition survey in 1995-96 reports that the overall prevalence of anemia in adolescent boys were $64.1 \%$ in the country. It has been observed from a research study that the prevalence of anemia among 
the adolescent boys in Dhaka City was $8.5 \%$ (1998 unpublished). The better economic and social background of the study population may be the responsible factor for the low prevalence of anemia. In the present study anemia was more prevalent among the malnourished (Thin and Overweight) children than those of the well nourished group having normal BMI. Another study (unpublished, 1998) of adolescent boys reveals that boys with normal BMI are less likely to have anemia compared with malnourished one. Inadequate dietary intake and/or low dietary bioavailability of iron are considered to be the most important factor contributing to the iron deficiency anemia. Haem iron in the diet increases absorption. The absorption of non-haem iron is influenced by the individual iron status: more iron is absorbed by iron deficient subjects ${ }^{10}$. Moreover, the absorption of non-haem iron is enhanced by dietary factors such as ascorbic acid, meat, fish. In the present study dietary intake of vitamin $\mathrm{C}$ was below $50 \%$ of RDA.

This study also indicates that the prevalence of overweight $(15.4 \%)$ is higher than the prevalence of thinness $(8.9 \%$ ) which may be considered as a risk factor for sound health in future. Overweight or obesity coexist with hypertension, heart disease and stroke. Health risks and complication associated with excess weight are responsible for premature death. In addition to the health hazard, it is not uncommon for overweight children to suffer psychological stress and social discrimination.

This study highlight the characteristic of the adolescent boys attending schools. The information obtained from this study may be used to design a randomized school program for the prevention of health defects and the promotion of healthful living.

\section{Reference:}

1. Sathyavati $\mathrm{K}$ and Agarwal $\mathrm{KN}$. Adolescent growth studies and growth characteristics. Ind. J.Paed. 19791 16:217.

2. Kurz KM. Adolescent nutritional status in developing countries. Proceedings of the nutrition society. 1996; 55:321-331.

3. Kurz KM and Johnson Welch. The nutrition and lives of adolescents in developing: findings from the nutrition of adolescent grils, research program. International Center for Research on Women. Washington DC; 1994.

4. Hossain MS. Status of adolescent girls of Bangladesh Bureau of Statistics. Ministry of Planning. Government of Peoples Republic of Bangladesh. 1995.

5. Dc Meyer E, Adiels-Tegman M. The prevalence of anemia in the world. World Health Statistics Quarterly. 1985;38: 302-316.

6. World Health Organization. Control of iron deficiency anemia in South East Asia. Report of an inter-country workshop. 11-14 December 1995, WHO. Regional office of South East Asia, New Dehli.

7. Van Kampen E and Zijlstra EG. Chem.Acta. 1961; 6: 538.

8. ICSH. International Committee for Standerization in human blood. Brit.J.Haemat. 1967; $13: 71$. 
9. Hyder SMZ, Chowdhury SA. Prevalence of anemia and intestinal parasites in rural community of Bangladesh. Research monograph series; 12;BRAC. Dhaka, Bangladesh.

10. Hallberg L. Bioavailability of dietary iron in man. Annual Review of Nutrition. 1981;1:123-147.

11. Does how much weigh affect how long you live? Mayo Clinic Health Letter. 13(12);4:1995. 